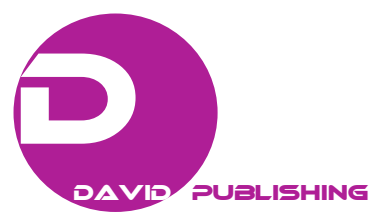

\title{
Factors that Affect Pellet Quality: A Review
}

\author{
Keysuke Muramatsu ${ }^{1}$, Andréia Massuquetto ${ }^{1}$, Fabiano Dahlke ${ }^{2}$ and Alex Maiorka ${ }^{1}$ \\ 1. Department of Animal Production, Faculty of Veterinary and Animal Science, Universidade Federal do Paraná, Curitiba \\ 80035-050, Brazil
}

2. Department of Animal Production, Faculty of Agronomy and Animal Science, Universidade Federal de Santa Catarina, Florianópolis 88040-900, Brazil

\begin{abstract}
Pelleting is the most popular thermal processing technique in poultry industry. Birds fed pelleted diets have greater feed intake and weight gain, and better feed conversion ratio. However, this better performance can only be achieved, if the pellets remain intact until they are ingested by the birds. Many factors may affect pellet physical quality, such as feed nutritional composition, ingredient particle size, conditioning temperature and time, feed moisture, etc.. Despite their importance, sometimes these factors are not managed properly, therefore, pelleted feed may not contain a high amount of intact pellets. In addition, the possible interactions among these variables may yield different responses in comparison with those expected when individual factors are considered. Very few experiments have been conducted to evaluate the impact of combined factors on pellet quality. This may be explained by the presence of many qualitative and quantitative factors in the manufacturing process. Research indicates that heat processing and feed formulation, especially fat inclusion level, are the factors which have the biggest influence on pellet quality. Strategies, such as the expansion process and fat inclusion restriction or post pellet liquid fat application could be implemented to produce high physical quality pellets. More research is needed to identify which factors have a positive or negative effect on pelleting process and to find new strategies to improve pellet physical quality.
\end{abstract}

Key words: Conditioning, broiler, feed formulation, particle size, pellet durability index, pellet quality, pelleting, moisture.

\section{Introduction}

Pelleting is the most used thermal processing method in poultry industry. The aim of pelleting processing is to agglomerate ingredients particles by mechanical action, in combination with moisture, pressure and temperature. Broilers fed pelleted diets present greater feed intake, better feed conversion ratio and greater weight gain [1-3]. The positive effect of pelleting on broiler performance is partly due to improved nutrients digestibility [4], increased feed consumption [5] and increased broilers resting time which favors lower energy expenditure in maintaining and increasing availability of net energy for production [6]. However, this better performance can only be achieved, if the pellets maintain their integrity until the time they are ingested by the birds.

Pellet quality is defined as the ability to resist

Corresponding author: Andréia Massuquetto, M.Sc., research fields: feed processing and poultry nutrition. fragmentation and abrasion during handling without breaking up and to reach feeders without generating a high proportion of fines [7, 8]. Pellet durability index (PDI) is one of the main parameters used to determine pellet quality, as it indicates the percentage of pellets that remain intact after being submitted to mechanical forces. Pellets are submitted to friction, impact and pressure during storage, transport and dispatch from the feed mill to the farms $[9,10]$, and poor-quality pellets disintegrate, resulting in a feed consisting of a few pellets and fines. The geometric mean diameter (GMD) of fine particles is equal or lower than that of mash diets, and these particles may cause a nutritional imbalance in feed chemical composition, which may negatively affect animal performance. Mckinney and Teeter [6] evaluated diets with different pellets and fines proportions, such as $100 \%, 80 \%, 60 \%, 40 \%$ and $20 \%$ of pellets, and $100 \%$ of fines on broilers performance, respectively. Birds fed $100 \%$ of pellets 
showed higher weight gain and better feed conversion, and the worst results were found in birds fed $100 \%$ of fines.

Several factors affect pellet quality, such as dietary nutritional composition, feedstuff particle size, conditioning time and temperature, feed moisture content, compression rate of pellet die, gap between the pellet press roll and die, etc. [11]. In addition, there may be interactions among these factors, producing different results in comparison with those expected when individual parameters are taken into account.

Considering the importance of pelleted diet quality for animal production, the objective of this review is to discuss the factors that influence pellet quality and their interactions.

\section{Factors that Affect Pellet Quality}

\subsection{Particle Size}

Particle size is the factor that causes the least influence on pellet quality [12]. Reducing particle size increases particle surface area relative to its volume, thereby increasing the number of contact sites among particles. As a result, interatomic adhesion forces increase (van der Waals forces, dipole-dipole forces, hydrogen bonding), as well as the capillarity between pellet solid-liquid phases and the penetration of heat and moisture to the centre of the feed particle, consequently reducing heat-treatment time [13, 14].

Dozier [1] suggests that for broiler diets based on corn and soybean meal, the optimal GMD for pellet durability should be between $650 \mu \mathrm{m}$ and $700 \mu \mathrm{m}$. Particles ground larger than 1,000-1,500 $\mu \mathrm{m}$ may produce pellet breaking points $[15,16]$. On the other hand, the larger surface area of low particle sizes favours heat and moisture transference to the mash inside the conditioner [9].

However, intense reduction of particle size of feedstuffs may not be beneficial to pellet quality. Fahrenholz [12] evaluated pelleted feeds formulated with corn with two different particle sizes (298 $\mu \mathrm{m}$ or $462 \mu \mathrm{m})$ and did not find any PDI differences. This lack of effect of particle size is possibly due to the fact that the evaluated GMD range was not sufficient to influence pellet quality. However, Wondra et al. [17] reported a PDI increase of $78.8 \%$ to $86.4 \%$ when particle size was reduced from $1,000 \mu \mathrm{m}$ to $400 \mu \mathrm{m}$. Therefore, significant reductions in particle size may affect pellet quality.

\subsection{Moisture Addition}

Both the water added to the mixer and that added as steam during conditioning aid pellet particle binding. This agglutinating capacity is based on water capillarity properties and surface tension [18].

Moritz et al. [19] evaluated the effect of heat treatment (conditioning-pelleting) on feeds containing $927 \mathrm{~g}$ or $853 \mathrm{~g}$ of moisture per kg of dry matter and obtained $56.5 \%$ and $82.2 \%$ PDI, demonstrating the beneficial effect of high moisture on pellet quality. Evaluating three levels of water addition to the mixer $(0,25$ or $50 \mathrm{~g} / \mathrm{kg})$, followed by conditioning for $10 \mathrm{~s}$ at $82.2{ }^{\circ} \mathrm{C}$ and subsequent pelleting, Moritz et al. [20] obtained increasing PDI values of 75.6\%, 76.9\% and $79.6 \%$, respectively. The positive effects on pellet quality of the addition of $20 \mathrm{~g}$ and $40 \mathrm{~g}$ of water per $\mathrm{kg}$ of feed in the mixer obtained by Buchanan [21] are consistent with those results. Abdollahi et al. [22] verified that the addition of $24 \mathrm{~g}$ of moisture/ $\mathrm{kg}$ of feed conditioned at $60{ }^{\circ} \mathrm{C}$ increased the PDI from $56.5 \%$ to $67.2 \%$.

However, water may act as a lubricant and reduce the friction between pellet die holes and the roller [12, 23-25], negatively affecting pellet durability. This was shown in the study of Colovic et al. [11], who evaluated different die height to hole diameter ratios $(18 / 6,36 / 6$, or $48 / 6 \mathrm{~mm})$, and the highest moisture content of the last treatment (16.2\%) annulled the progressive improvement of pellet durability expected with increasing die heights.

\subsection{Fat Inclusion}

High dietary fat content may result in less durable 
pellets $[8,12,20,26]$. Fat reduces the contact of the meal with die-hole walls, facilitating feed passage through the die and thereby reducing feed compaction inside the die holes [12]. The addition of fat before conditioning causes partial encapsulation of feed particles and hinders the penetration of steam, which thus reduces starch gelatinization and weakens capillary adhesion forces [9, 12].

The amount of added fat should be limited to $5-10 \mathrm{~g}$ per $\mathrm{kg}$ of feed, if a high percentage of intact pellets is required [27]. Moritz et al. [19] evaluated two oil addition levels $(30 \mathrm{~g} / \mathrm{kg}$ and $65 \mathrm{~g} / \mathrm{kg}$ ) in broiler diets and observed that PDI was reduced from $81.6 \%$ to 62.1\% with the highest oil level. Fairfield [28] and the report of California Pellet Mill Co. [13] mentioned that adding more than $20 \mathrm{~g}$ of fat per $\mathrm{kg}$ of feed in the mixer previous to pelleting decreases the PDI of diets based on corn and soybean meal. Briggs et al. [8] also reported that when dietary ether extract increased from $29 \mathrm{~g} / \mathrm{kg}$ to $75 \mathrm{~g} / \mathrm{kg}$, PDI was reduced from $88.8 \%$ to $57.2 \%$.

The post pellet liquid fat application (PPLA) of supplemental fat is an alternative to maintain the integrity of the pellets. Schramm et al. [29] evaluated increasing levels of fat inclusion in the mixer $(10,15$, $20,25,30$ and $35 \mathrm{~g} / \mathrm{kg}$ ) and the application of supplemental fat by PPLA method $(0,5,10,15,20$ and $25 \mathrm{~g} / \mathrm{kg}$ ) to complete $35 \mathrm{~g}$ of fat per $\mathrm{kg}$ of feed on PDI. The PPLA increased the PDI from 86\%, when all the fat was added in the mixer, to $97 \%$ with $25 \mathrm{~g}$ of fat per $\mathrm{kg}$ of feed added post pellet. The optimal level of PDI was obtained with $23.3 \mathrm{~g}$ of fat per $\mathrm{kg}$ of feed added post pellet and $11.7 \mathrm{~g} / \mathrm{kg}$ added in the mixer.

\subsection{Conditioning}

Conditioning is essential to obtain good physical quality of the feed. During conditioning, steam breaks down the structure of starch, resulting in its gelatinization, as well as changes protein tertiary structure. Starch gelatinization combined with protein plasticization allows binding among feed particles, and thereby it is important for the manufacturing of durable pellets [30].

Abdollahi et al. [31] evaluated the effect of conditioning temperature on the pellet quality of broiler diets based on corn or sorghum, and observed that when increasing the temperature from $75{ }^{\circ} \mathrm{C}$ to $90{ }^{\circ} \mathrm{C}$ the PDI improved in both diets. Evaluating different feed retention times in the conditioner, Briggs et al. [8] reported that increasing retention time from $5 \mathrm{~s}$ to $15 \mathrm{~s}$ increased pellet durability in $4.5 \%$. Skoch et al. [23] stated that the addition of moisture using steam improves pellet quality by reducing the proportion of fines and increasing pellet durability.

Feed expansion after conditioning may be an alternative to improve pellet quality by adding expansion benefits to pelleting. Exposure to high pressure and temperature for a short time may lead to an improvement in bioavailability of hard to digest feed components [32]. In the experiment of Lundblad et al. [33], when the effect of heat treatment on the pellet quality of corn-based broiler diets by conditioning feed at $82{ }^{\circ} \mathrm{C}$ for $30 \mathrm{~s}$ was compared to conditioning under the same conditions followed by expansion at $121{ }^{\circ} \mathrm{C}$, a PDI improvement of $81.8 \%$ to 92.3\% was obtained. Also, Fancher et al. [32] compared the PDI of broiler and turkey feeds of nine US feed mills before and after the installation of expanders, and reported that it improved from $72 \%$ to $89 \%$.

\section{Interaction among Different Factors on Pellet Quality}

Several factors may affect pellet quality individually or in different combinations. Therefore, each factor and its interactions with other factors should be known to allow understanding their influence on the quality of pelleted diets.

Reimer [34] determined the following partitioning of the effects of different factors (particle size, conditioning, pellet press die, cooling/drying, and feed formulation) on pellet durability: $5 \%$ due to cooling/ 


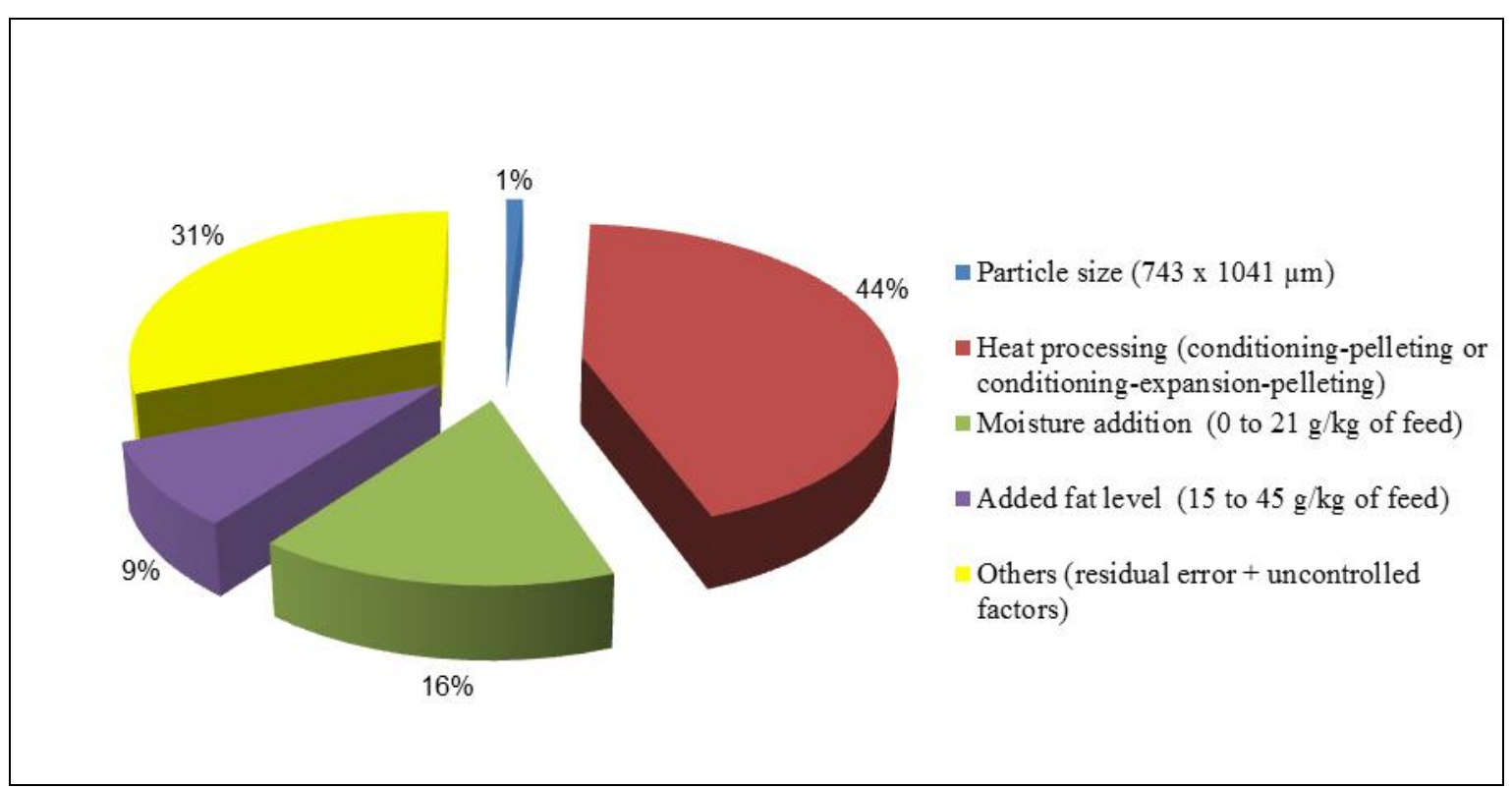

Fig. 1 Effect of different factors on PDI.

drying processes, $15 \%$ due to pellet press die specifications, $20 \%$ due to heat conditioning and $40 \%$ due to feed formulation. These ratios were calculated using European diets, which possibly contain winter cereals.

Muramatsu [35] evaluated the effect of the interactions among different factors on the pellet quality (PDI) of diets based on corn and soybean meal, including particle size (743 $\mu \mathrm{m}$ and 1,041 $\mu \mathrm{m})$, heat processing (conditioning-pelleting or conditioning-expansion-pelleting), moisture addition $(0,7,14$, and $21 \mathrm{~g}$ of water per $\mathrm{kg}$ of feed) and added fat level (15, 25, 35 and $45 \mathrm{~g}$ of fat per $\mathrm{kg}$ of feed). When modelling the effect of all factors, heat processing was the factor that most influenced pellet quality, accounting for $44 \%$ of the observed PDI variability (Fig. 1). Under the conditions of that study, the most efficient alternative to improve pellet quality was diet expansion after conditioning, followed by, in decreasing order, increasing moisture level addition, fat inclusion restriction and finally particle size reduction.

\section{Conclusions}

Improving the efficiency of the pelleting process to produce high PDI pellets has been a permanent focus of the work of feed mill managers, production engineers and nutritionists. Despite the significant corpus of knowledge built in the last few years, further research on the interaction of factor that affect pellet quality is needed.

Strategies, involving changes in diet formulation, feedstuff particle size and adjustment of conditioning parameters, may be implemented to improve pellet quality. The research indicates that heat processing and feed formulation, especially fat inclusion level, are the factors which have the biggest influence on pellet quality.

Alternative procedures, such as the expansion process, increasing moisture level addition, fat inclusion restriction or post pellet liquid fat application, could be incorporated into the feed mill to produce high physical quality pellets.

\section{References}

[1] Dozier III, W. A. 2001. “Cost Effective Pellet Quality for Meat Birds.” Feed Management 52 (2): 1-3.

[2] Freitas, E. R., Sakomura, N. K., Dahlke, F., Santos, F. R., and Barbosa, N. A. A. 2008. "Performance, Efficiency of Nutrient Utilization and Gastrointestinal Structures of Broiler Chick Fed in Prestarter Phase with Ratios with 
Different Physical Form.” Brazilian Journal of Animal Science 37 (1): 73-8.

[3] Corzo, A., Mejia, L., and Loar II, R. E. 2011. "Effect of Pellet Quality on Various Broiler Production Parameters.” Journal Applied of Poultry Research 20: 68-74.

[4] Zalenka, J. 2003. "Effect of Pelleting on Digestibility and Metabolizable Energy of Poultry Diets.” In Proceedings of European Symposium on Poultry Nutrition, 127-8.

[5] Meinerz, C., Ribeiro, A. M. L., Penz Jr, A. M., and Kessler, A. M. 2001. "Energy Level and Pelleting on Performance and Carcass Yield of Pair-Fed Broilers.” Brazilian Journal of Animal Science 30 (6): 2026-32.

[6] Mckinney, L. J., and Teeter, R. G. 2004. "Predicting Effective Caloric Value of Nonnutritive Factors: Part I, Pellet Quality and Part II, Prediction of Consequential Formulation Dead Zones.” Poultry Science 83 (7): 1165-74.

[7] Amerah, A. M., Ravindran, V., Lentle, R. G., and Thomas, D. G. 2007. "Feed Particle Size: Implications on the Digestion and Performance in Poultry." World's Poultry Science 63 (3): 439-51.

[8] Briggs, J. L., Maier, D. E., Wakins, B. A., and Behnke, K. C. 1999. "Effect of Ingredients and Processing Parameters on Pellet Quality.” Poultry Science 78: 1464-71.

[9] Lowe, R. 2005. "Judging Pellet Stability as Part of Pellet Quality.” Feed Tech. 9 (2): 15-9.

[10] Mina-Boac, R. J., Maghirang, G., and Casada, M. E. 2006. "Durability and Breakage of Feed Pellets during Repeated Elevator Handling.” Presented at ASABE Annual International Meeting, ASABE, July 9-12, 2006, Portland, Oregon.

[11] Colovic, R., Vukmirovic, D., Matulaitis, R., Bliznikas, S., Uchockis, V., Juskiene, V., and Levic, J. 2010. "Effect of Die Channel Press Way Length on Physical Quality of Pelleted Cattle Feed.” Food \& Feed Research 37 (1): 1-6.

[12] Fahrenholz, A. C. 2012. "Evaluating Factors Affecting Pellet Durability and Energy Consumption in a Pilot Feed Mill and Comparing Methods for Evaluating Pellet Durability.” Ph.D. thesis, Kansas Universtiy, Manhattan, Kansas.

[13] California Pellet Mill Co.. 2012. "The Pelleting Process.” Accessed July, 2015. http://ww1.prweb.com/prfiles/ 2012/01/09/9090113/Animal\%20Feed\%20Pelleting.PDF.

[14] Behnke, K. C. 2006. The Art (Science) of Pelleting. Technical Report Series: Feed Technology, American Soya Association, Singapore.

[15] Franke, M., and Rey, A. 2006. "Improving Pellet Quality and Efficiency.” Feed Tech. 10 (3): 12-5.

[16] Acedo-Rico, J., Méndez, J., and Santomá, G. 2010. "Feed Manufacturing.” In The Nutrition of the Rabbit, edired by De Blas, C., and Wiseman, J. Wallingford, Oxford: CAB Publishing, 200-21.
[17] Wondra, K. J., Hancock, J. D., Behnke, K. C., Hines, R. H., and Stark, C. R. 1995. "Effects of Particle Size and Pelleting on Growth Performance, Nutrient Digestibility, and Stomach Morphology in Finishing Pigs.” Journal of Animal Science 73 (3): 757-63.

[18] Froetschner, J. 2006. "Conditioning Controls Quality of Pellet.” Feed Tech. 10 (6): 12-5.

[19] Moritz, J. S., Wilson, K. J., Cramer, K. R., Beyer, R. S., Mckinney, L. J., Cavalcanti, W. B., and Mo, X. 2002. "Effect of Formulation Density, Moisture and Surfactant on Feed Manufacturing, Pellet Quality and Broiler Performance.” Journal Applied of Poultry Research 11: 155-63.

[20] Moritz, J. S., Cramer, K. R., Wilson, K. J., and Beyer, R. S. 2003. "Feed Manufacture and Feeding of Rations with Graded Levels of Added Moisture Formulated to Different Energy Densities.” Journal Applied of Poultry Research 12 (3): 371-81.

[21] Buchanan, N. P. 2008. "Diet Formulation and Manufacturing Technique Interactions Affect Pellet Quality and Broiler Growth.” Ph.D. thesis, West Virginia University.

[22] Abdollahi, M. R., Ravindran, V., Wester, T. J., Ravindran, G., and Thomas, D. V. 2012. "Effect of Improved Pellet Quality from the Addition of a Pellet Binder and/or Moisture to a Wheat-Based Diet Conditioner at Two Different Temperatures on Performance, Apparent Metabolisable Energy and Ileal Digestibility of Starch and Nitrogen in Broilers.” Anim. Feed Sci. Technol. 175 (3-4): 150-7.

[23] Skoch, E. R., Behnke, K. C., Deyoe, C. W., and Binder, S. F. 1981. "The Effect of Steam-Conditioning Rate on the Pelleting Process.” Animal Feed Science and Technology 6 (1): 83-90.

[24] Ziggers, D. 2003. "Die Determines the Pellet Production.” Feed Tech. 7 (8): 17-9.

[25] Cutlip, S. E., Hott, J. M., Buchanan, N. P., Rack, A. L., Latshaw, J. D., and Moritz, J. S. 2008. "The Effect of Steam-Conditioning Practices on Pellet Quality and Growing Broiler Nutritional Value.” Journal Applied of Poultry Research 17: 249-61.

[26] Thomas, M., Viliet, T., and Van der Poel, A. F. B. 1998. "Physical Quality of Pelleted Animal Feed: Part 3, Contribution of Feedstuffs Components.” Animal Feed Science Technology 70 (1-2): 59-78.

[27] Leaver, R. H. 2008. “The Pelleting Process.” Accessed August 2015. http://www.andritzsproutbauer.com/pdf/ The-Pelleting-Process-v2008.pdf.

[28] Fairfield, D. A. 2003. "Pelleting for Profit Part 1.” Feed and Feeding Digest, National Grain and Feed Association Part 1, No. 6. Accessed August 2015. http://nmfeed.com/Files/Posts/Portal1/4(30).pdf. 
[29] Schramm, V. G., Natel, J. C. C., Panisson, J. C., Silva, R. S. A., Santos, R. O. F., and Maiorka, A. 2015. "Post-Pellet Oil Levels on Diet Physical Quality.” In Proceedings of the Latin American Trade Fair for the Poultry and Swine Industry.

[30] Behnke, K. 1994. "Factors Affecting Pellet Quality.” In Proceedings of the Maryland Nutrition Conference, 44-54.

[31] Abdollahi, M. R., Ravindran, V., Wester, T. J., Ravindran, G., and Thomas, D. V. 2010. "Influence of Conditioning Temperature on Performance, Apparent Metabolisable Energy, Ileal Digestibility of Starch and Nitrogen and the Quality of Pellets, in Broiler Starters Fed Corn and Sorghum-Based Diets.” Animal Feed Science and Technology 162: 106-15.

[32] Fancher, I., Rollins, D., and Trimbe, B. 1996. "Feed
Processing Using the Annular Gap Expander and Its Impact on Poultry Performance.” J. Appl. Poult. Res. 5 (4): 386-94.

[33] Lundblad, K. K., Hancock, J. D., Behnke, K. C., Prestløkken, E., McKinney, L. J., and Sørensen, M. 2009. "The Effect of Adding Water into the Mixer on Pelleting Efficiency and Pellet Quality in Diets for Finishing Pigs without and with Use of an Expander.” Anim. Feed Sci. Technol. 150 (3-4): 295-302.

[34] Reimer, L. 1992. “Conditioning.” Presented at Northern Crops Institute Feed Mill Management and Feed Manufacturing Technology, Short Course, California Pellet Mill Co., Crawfordsville, Indiana.

[35] Muramatsu, K. 2013. "Predictive Modeling Application in Pelleting Process of the Feed for Broilers.” Ph.D. thesis, Universidade Federal do Paraná, Curitiba. 